\title{
Gambaran Pengetahuan Keluarga Tentang Kegawatdaruratan Hipoglikemia Pada Penderita Diabetes Melitus di Wilayah Kerja Puskesmas Cakranegara
}

\author{
Musniati $^{1 *}$, Ega Aprilia ${ }^{1}$ \\ ${ }^{1}$ Jurusan Ilmu Keperawatan, Universitas Nahdlatul Wathan Mataram \\ *Email : musniati.suseno@gmail.com
}

\begin{abstract}
Abstrak : Hipoglikemia merupakan penyakit kegawatdaruratan yang membutuhkan penanganan segera, karena jika terlambat bisa mengakibatkan penurunan kesadaran, kejang hingga kerusakan permanen pada otak. Sehingga peran keluarga sangat penting dalam mengenal keadaan kesehatan dan perubahan-perubahan yang dialami anggota keluarga. Hal tersebut dapat meminimalisir komplikasi dan kematian pada anggota keluarga yang sakit. Tujuan penelitian ini untuk mengetahui gambaran pengetahuan keluarga tentang kegawatdaruratan hipoglikemia pada penderita diabetes mellitus. Jenis penelitian ini adalah deskriptif dengan instrumen penelitian menggunakan kuesioner. Tehnik sampel yang digunakan dalam penelitian ini adalah Purposive Sampling dengan jumlah sampel 30 responden.. Hasil penelitian menunjukkan pengetahuan keluarga kurang yang dipengaruhi oleh karakteristik responden yaitu usia, pendidikan dan jenis kelamin. Tugas dan peran keluarga begitu kompleks, hal ini dapat menyebabkan kurangnya perhatian keluarga terhadap keluarga yang sakit. Peningkatan pengetahuan perlu diberikan seperti kunjungan rumah oleh tenaga kesehatan sebagai bentuk perhatian agar keluarga dapat menentukan manajemen dan perilaku apa yang harus digunakan untuk mengatasi penyakit anggota keluarga.
\end{abstract}

Kata kunci : Pengetahuan Keluarga dan Kegawatdaruratan Hipoglikemia pada Diabetes Mellitus

\section{Pendahuluan}

Menurut Saeedi P pada tahun 2019 melaporkan bahwa prevalensi diabetes mellitus (DM) secara global akan terus mengalami peningkatan dari $9,3 \%$ menjadi $10,2 \%$ dan diperkirakan juga dari tahun 2030 sampai dengan 2045 kasus DM tetap akan meningkat. Sedangkan di Indonesia menjadi negara peringkat keenam di dunia setelah Tiongkok, India, Amerika Serikat, Brazil dan Mesiko dengan jumlah penyandang DM usia 20-79 tahun sekitar 10,3 juta orang (Depkes, 2018). Menurut data di Puskesmas Cakranegara terdapat tahun 2020 sebayak 280 penderita.

Pada penderita DM yang paling dikhawatirkan adalah terjadinya komplikasi hipoglikemia, karena termasuk dalam penanganan kegawatdaruratan. Hipoglikemia terjadi akibat gula darah dibawah normal < $70 \mathrm{mg} / \mathrm{dl}$. Gejala hipoglikemia akan terasa seseorang mengalami gula darah < 70 mg/dl ( Permatasari, Desy Ayu, 2020).

Hipoglikemia membutuhkan penanganan dengan cepat dan tepat sehingga tidak berdampak pada kerusakan organ utama manusia terutama otak. Penurunan kadar glukosa darah dibawah normal akan berdampak secara akut pada fungsi otak karena otak sangat tergantung pada glukosa, otak tidak dapat menyimpan cadangan glukosa untuk proses metabolisme. Sel otak akan mengalami iskemia apabila tidak mendapatkan oksigen dan glukosa 4-6 menit, serta dapat menimbulkan kerusakan otak yang bersifat irreversibel jika lebih dari 10 menit. Selain itu hipoglikemia dapat mengancam kehidupan, secara psikologis hipoglikemia juga memberi dampak negatif bagi pasien dan pengelolaan diabetes melitusnya (Setyawati, 2016 dalam Permatasari, Desy Ayu, 2020).

Sifat dari penanganan kegawatdarutan adalah segera maka keluarga perlu mengetahui tanda dan gejala secara umum dari penderita hipoglikemia sehingga keluarga dapat segera membawa penderita ke Rumah Sakit dimana hal ini juga sesuai dengan tugas keluarga yaitu mengenal masalah kesehatan keluarga (Dion \& Betan, 2013). Sehingga peneliti perlu mengaetahui gambaran pengetahuan keluarga tentang kegawatdaruratan hipoglikemia pada penderita DM di Wilayah Kerja Puskesmas Cakranegara.

\section{Metode Penelitian}

Jenis penelitian yang digunakan dalam penelitian ini adalah bersifat deskriptif, pengumpulan data dengan cara pemberian kuesioner. 


\section{Hasil dan Pembahasan}

\section{Hasil}

a. Karakteristik responden

Tabel 1. Distribusi responden berdasarkan usia

\begin{tabular}{clcc}
\hline No & Tingkat usia & Frekuensi & Presentase \\
\hline $\mathbf{1}$ & $\begin{array}{l}\text { Dewasa awal } \\
(26-35)\end{array}$ & 9 & $30 \%$ \\
$\mathbf{2}$ & $\begin{array}{l}\text { Dewasa akhir } \\
(36-45)\end{array}$ & 6 & $20 \%$ \\
$\mathbf{3}$ & $\begin{array}{l}\text { Lansia awal } \\
(46-55)\end{array}$ & 2 & $\mathbf{7 \%}$ \\
$\mathbf{4}$ & $\begin{array}{l}\text { Lansia akhir } \\
(56-65)\end{array}$ & 12 & $\mathbf{3 0 \%}$ \\
$\mathbf{5}$ & $\begin{array}{l}\text { Manula } 66 \\
\text { keatas } \\
\text { Jumlah }\end{array}$ & $\mathbf{3 0}$ & $\mathbf{1 0 0 \%}$ \\
\hline
\end{tabular}

Tabel 2 Distribusi responden berdasarkan pendidikan

\begin{tabular}{cccc}
\hline No & $\begin{array}{c}\text { Tingkat } \\
\text { pendidikan }\end{array}$ & Frekuensi & Presentase \\
\hline $\mathbf{1}$ & SMP & 18 & $60 \%$ \\
$\mathbf{2}$ & SMA & 12 & $40 \%$ \\
\hline & Jumlah & $\mathbf{3 0}$ & $\mathbf{1 0 0 \%}$ \\
\hline
\end{tabular}

Tabel 3 Distribusi responden berdasarkan jenis kelamin

\begin{tabular}{cccc}
\hline No & $\begin{array}{c}\text { Jenis } \\
\text { kelamin }\end{array}$ & Frekuensi & Presentase \\
\hline $\mathbf{1}$ & Laki laki & 18 & $60 \%$ \\
$\mathbf{2}$ & Perempuan & 12 & $40 \%$ \\
& Jumlah & $\mathbf{3 0}$ & $\mathbf{1 0 0 \%}$ \\
\hline
\end{tabular}

b. Pengetahuan Hipoglikemia Responden

Tabel 4 Distribusi responden berdasarkan pengetahuan

\begin{tabular}{clcc}
\hline No & Pengetahuan & Frekuensi & Presentase \\
\hline $\mathbf{1}$ & Baik & 3 & $10 \%$ \\
$\mathbf{2}$ & Cukup & 9 & $30 \%$ \\
$\mathbf{3}$ & Kurang & 18 & $60 \%$ \\
& Jumlah & $\mathbf{3 0}$ & $\mathbf{1 0 0 \%}$ \\
\hline
\end{tabular}

\section{Pembahasan}

Hasil penelitian ini menunjukkkan mayoritas responden berpengatahuan kurang. Hal ini juga dipengaruhi oleh tugas keluarga, dimana tugas keluarga yang baik dipengaruhi oleh karakteristik responden dalam penelitian. Karakteristik responden dalam penilitian ini adalah usia, pendidikan dan jenis kelamin.

$$
\text { Distribusi karakteristik responden }
$$
berdasarkan usia pada penelitian ini mayoritas responden usia lansia akhir. Hal ini sesuai dengan penelitian Ingga (2010) dalam Rudiyana IW (2017) bahwa saat semakin cukup umur tingkat kematangan dan kekuatan seseorang akan lebih matang dalam berfikir dan bekerja. Tapi tidak sejalan dengan yang dinyatakan Verner dan Davison bahwa adanya faktor fisik yang dapat menghambat proses belajar pada orang dewasa, sehingga membuat penurunan pada suatu waktu dalam kekuatan berfikir dan bekerja. Sedangkan pada lansia secara fisiologis akan mengalami kematian sel-sel otak dan sinapsis sehingga berdampak buruk pada daya ingat. Lansia bisa mengalami kesulitan untuk mempelajari hal- hal baru dan mudah melupakan informasi di bandingkan dengan dewasa awal.

Distribusi karakteristik responden pendidikan menunjukkan mayoritas pendidikan SMP. Hal ini sesuai dengan penelitiannya Wahyuni K.I (2019) dimana pendidikan terendah SD sampai SMP menduduki jumlah terbanyak yang artinya rendahnya pengetahuan pasien maupun keluarga yang mendampingi dapat berdampak terhadap keterlaksanaan pengelolaan diabetes mellitus. Menurut Maharani (2014) menyatakan bahwa baiknya pengetahuan dapat dipengaruhi oleh beberapa faktor diantaranya faktor pendidikan, pendidkan sangat mempengaruhi terhadap pengetahuan sesorang karena pendidikan merupakan suatu proses pembelajaran pola pikir sesorang dari tidak tahu menjadi tahu, dari jenjang pendidikan inilah dapat diketahui pola pikir seseorang, semakin tinggi pendidikan maka ilmu yang diperoleh akan semakin banyak (Rudiyana IW, 2017). Menurut Bertalina \& Purnama (2016) pengetahuan yang kurang baik ini mengacu pada responden yang kurang memahami tanda dari hipoglikemia yaitu pucat, lemas, merasa lapar, gemetar, keringat berlebih dan jantung berdebar.

Distribusi karakteristik responden menunjukkan mayoritas jenis kelamin adalah lakilaki, tetapi pada hasil pengelolaan data menunjukkan perbedaan tingkat pengetahuan dimana tingkat pengetahuan perempuan lebih tinggi dibandingkan tingkat pengetahuan laki-laki. Hal ini dapat dilihat pada tingginya persentase laki-laki dengan tingkat pengetahuan berkategori kurang dibandingkan perempuan. Menurut Friedman (2010) dalam Tri Astuti (2013) anggota keluarga khususnya perempuan mempunyai peranan penting sebagai caregiver primer pada pasien. Perempuan dalam peranannya sebagai ibu, tentunya mempunyai naluri perasaan yang lebih peka dalam merawat anggota keluarganya yang sakit. Perempuan dalam kondratnya diciptakan lebih sabar, telaten dan penuh kasih sayang. Begitu juga bagi perempuan yang merawat anggota keluarga dengan hipertensi, mereka dengan sabar merawat dan menemani pasien untuk berobat. Perempuan memiliki perananan sebagai health provider atau penyedia kesehatan yaitu orang yang menjaga sekaligus merawat dan mencari pengobatan untuk keluarganya (Fridman, 2010). Seringkali dikatakan 
bahwa perempuan berperan sebagai role models bagi anggota keluarganya untuk hidup sehat karena dalam kehidupan sehari-hari perempuan banyak terlibat dalam sistem perawatan keluarga.

\section{Kesimpulan}

Hasil penelitian didapatkan gambaran pengetahuan keluarga tentang kegawatdaruratan hipoglikemia pada penderita diabetes melitus dalam kategori pengetahuan kurang $(60 \%)$, pengetahuan baik $(10 \%)$,pengetahuan cukup $(30 \%)$

\section{Daftar Pustaka}

Bertalina, B., \& Purnama, P. (2016). Hubungan Lama Sakit, Pengetahuan, Motivasi Pasien dan Dukungan Keluarga dengan Kepatuhan Diet Pasien Diabetes Mellitus. Jurnal Kesehatan, 7(2), 329-340. https://doi.org/10.26630/jk.v7i2.211

Depkes (2018). Data dan informasi profil Kesehatan Indonesia. https://pusdatin.kemkes.go.id/resources/dow nload/pusdatin/profil-kesehatanindonesia/Data-dan-Informasi_ProfilKesehatan-Indonesia-2018.pdf

Permatasari, Desy Ayu (2020). Studi Literatur Identifikasi Faktor yang mempengaruhi Kejadian Hipoglikemia pada Pasien Diabetes Melitus. Universitas Muhammaddiyah Malang. http://eprints.umm.ac.id/id/eprint/68307

Rudiyana IW, Purwanto E \& Setiawan (2017). Faktor-faktor yang Mempengaruhi Pengetahuan Keluarga tentang Penganan Hipoglikemia pada Pasien Diabetes. Perpustakaan Poltekkes Kemenkes kaltim. http://repository.poltekkeskaltim.ac.id/id/eprint/752

Saeedi P, Petersohn I, Salvea p, et al, (2019). Global and regional diabetes prevalence estimates for 2019 and projections for 2030 and 2045: Results from the International Diabetes Federation Diabetes Atlas, 9th edition, vol.157, Elsevier. https://www.sciencedirect.com/science/articl e/pii/S0168822719312306.

Silalahi, L. (2019). Hubungan Pengetahuan dan Tindakan Pencegahan Diabetes Mellitus Tipe 2 Correlation Between Knowledge And Precaution Diabete Mellitus Type 2. Jurnal Promkes: The Indonesian Journal of Health Promotion Ad Health Education, 7(2), 223232.

https://doi.org/10.20473/jpk.V7.I2.2019.223 $-232$

Tri Astuti (2013). Hubungan Tingkat Pengetahuan Keluarga dengan Tugas Kesehatan Keluarga dalam Merawat lansia Penderita Diabetes Melitus di Puskesmas Temon 1 Kulon Progo.
http://repository.unjaya.ac.id/894/1/Tri\%20 Astuti_3209027_nonfull.pdf

Wahyuni, K. I., Prayitno, A. A., \& Wibowo, Y. I. (2019). Efektivitas Edukasi Pasien Diabetes Mellitus Tipe 2 Terhadap Pengetahuan dan Kontrol Glikemik Rawat Jalan di RS Anwar Medika. Jurnal Pharmascience, 6(1), 1. https://doi.org/10.20527/jps.v6i1.6069

Yohanes Dion, Yaseinta Betan.( 2013). Asuhan Keperawatan Keluarga Konsep Dan Praktik. Yogyakarta: Nuha Medika 